\title{
Outcomes from the Components of an Outward Bound Experience
}

\author{
Marni Goldenberg, Leo McAvoy, and David B. Klenosky
}

Means-end theory provides a useful approach for characterizing the relationship among the attributes or components of an experiential education course (the "means"), the benefits, or the outcomes associated with these attributes/course components, and the personal values (the "ends") these outcomes help to reinforce for course participants. The purpose of this article is to show how this "means-end" perspective can enhance our understanding of the outcomes associated with outdoor adventure programming. A self-administered questionnaire designed to identify the linkages among program attributes (i.e., course components), course outcomes, and personal values was administered to a sample of 216 Outward Bound course participants. Analysis of the data provided useful insights into the outcomes associated with Outward Bound course experiences and with specific course components. The results can assist experiential educators in linking outdoor adventure course outcomes to course components, and in marketing course programs to potential clients.

Keywords: Outdoor Adventure, Outward Bound, Course Components, Means-End Theory

Marni Goldenberg, Ph.D., is an Assistant Professor at California Polytechnic

State University, San Luis Obispo. She has worked in the field of outdoor/experiential education for the past 12 years. E-mail: mgoldenb@calpoly.edu

Leo McAvoy, Professor, School of Kinesiology, University of Minnesota, Minneapolis. E-mail: mcavo001@umn.edu

Dr. David B. Klenosky is an Associate Professor of Recreation and Sport Management at Purdue University in West Lafayette, Indiana. His e-mail address is: klenosky@purdue.edu 


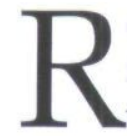

esearchers have been particularly interested in exploring the benefits and outcomes associated with participating in outdoor activiies (Driver, Nash, \& Haas, 1987; Roggenbuck \& Driver, 2000) and outdoor adventure education programs (Ewert \& McAvoy, 2000). The present research builds on this base by examining the outcomes of outdoor adventure education programs using an approach known as means-end analysis. Means-end theory provides a framework and methodology for identifying the important attributes of a particular product or service, the consequences (i.e., benefits and outcomes) associated with those attributes, and the personal values those consequences help reinforce for the individual (Gutman, 1982; Klenosky, Gengler, \& Mulvey, 1993).

Applications of means-end theory have typically focused on exploring the decision-making behavior of consumers. For instance, means-end studies were conducted to investigate the factors involved in purchasing a greeting card (Walker \& Olson, 1991), selecting a ski destination (Klenosky et al., 1993), choosing among interpretive services and programs (Klenosky, Frauman, Norman, \& Gengler, 1998), and exploring the factors influencing greenway/trail use (Frauman \& Cunningham, 2001).

Means-end analysis was recently applied to examine the benefits and outcomes associated with ropes course programming (Goldenberg, Klenosky, O'Leary, \& Templin, 2000). This study was unique because it was the first to apply means-end theory to examine the factors associated with participation in a recreation activity, as opposed to those involved in product or service decision-making. It was also the first means-end study involving both an experiential education activity and an outdoor adventure education setting. Although the Goldenberg et al. study provided useful insights about the means-end relationships among the outcomes and values associated with completing a ropes course program, the adventure education setting involved in the study was narrow in both scope and duration. Most of the respondents in the Goldenberg et al. study participated in a half-day program involving a portable low-elements ropes course, while other respondents participated in a similar, but full-day program, that also included a small number of high-elements. Both courses were conducted in university-based, non-wilderness settings. Consequently, researchers have yet to apply the means-end approach to examine the outcomes associated with a more comprehensive multi-day outdoor adventure experience conducted in a wilderness setting, such as an Outward Bound course. 
In sum, the present research builds on the foundation provided by the earlier ropes course study (Goldenberg et al., 2000) by examining a broader experiential education experience. The specific research objective was to use the means-end approach to better understand the outcomes and related meanings associated with completing an Outward Bound course, as well as to explore differences in the outcomes and means-end linkages for five key course components: rock climbing, interactions, expeditioning, campcraft skills, and the solo experience.

This article begins by providing background on the Outward Bound program, a review of prior research examining the outcomes of outdoor adventure education programming, and an overview of the means-end approach. Next, the findings from the present study are described. The final section summarizes the study's contributions to the experiential education literature, discusses implications for experiential education practitioners, and outlines future research directions.

\section{Background}

\section{Outward Bound}

Founded in 1941, Outward Bound was designed for men to gain physical fitness, craftsmanship, self-reliance, and compassion. These four core values are still pillars of Outward Bound programs today. Hattie, Marsh, Neill, and Richards (1997) reported that in 1994 over 40,000 individuals participated in Outward Bound programs worldwide. Over the years, Outward Bound has offered courses for women, youth, co-ed groups, and a variety of specialized groups. Outward Bound has played a key role in the outdoor education movement in North America, and has helped set standards for adventure programming in terms of safety, program design, and leadership (Hirsch, 1999).

\section{Previous Research on Outdoor Adventure Experiences}

Prior research confirms that outdoor adventure experiences typically involve elements of uncertainty, perceived risk, excitement, interaction with nature, and effort (Bunting, 1990; Ewert, 1989; Priest, 1990; Raiola \& O'Keefe, 1999). Research has also illustrated that outdoor adventure programs influence participants' awareness of themselves and others (Hattie et al., 1997). Other research has examined issues related to group dynamics and development, and found that outdoor adventure programs have positive effects on groups (Ewert \& Heywood, 1991; Fielding \& Hogg, 1997). Sibthorp's (2003) study included an analysis of the learning that was transferable from the program outcomes for 18 adolescents who completed a wilderness-based course. He concluded that students did learn "both hard and life skills by watching others succeed and fail, and from 
verbal feedback by staff and peers" (Sibthorp, p. 154). Todd, Anderson, Young, and Anderson (2002) examined the changes in motivations for outdoor adventure recreation activities over time for participants with varying levels of development. They concluded that, "beginners struggle to achieve, intermediates are drawn more by excitement and risk, advanced participants focus on self-actualization, and experts seek new challenges to stay involved" (Todd et al., p. 2). Neill and Richards (1998) did a summary of three different meta-analyses that represented over 12,000 participants. Their study showed that outdoor education programs did have a small to medium impact on outcomes that are typically measured, such as locus of control, self-confidence, and self-concept.

Hattie et al. (1997) examined the effects of adventure programs, specifically Outward Bound, and concluded that Outward Bound programs can have a positive effect on participants' self-esteem. Martin (2001) indicated that the main outcomes for participants, relative to the course objectives of an Outward Bound course, were personal and interpersonal development, specially improved self-confidence, and better interpersonal relationships. In one of the few investigations relating specific Outward Bound course components to program outcomes, Estes (1994) asked Outward Bound course instructors and participants to indicate the congruence between course components and eleven core values or principles. Her results showed that some course components (specifically those associated with daily activities, such as food preparation, setting up camp, etc., as well as group expeditions, and final expedition) were useful for conveying all eleven principles, while other components (rock climbing, rappelling, and ropes courses) tended to emphasize a more specific subset of principles. While Estes' study provides a useful foundation, several have noted that additional research is needed to refine our understanding about how and why program elements contribute towards specific program outcomes (Ewert, 1987; Hattie et al., 1997). As noted by Ewert, research is needed to provide "an understanding as to why (specific outcomes) happened and how (these outcomes) can be made to happen again" (p. 5). The means-end approach, outlined in the following section, has proven useful for examining the "how and why" issues in the context of outdoor adventure programming.

\section{Means-End Theory, Concepts and Relationships}

Means-end theory was originally developed to better understand how consumers or participants feel about a particular product or service (Gutman, 1982; Reynolds \& Gutman, 1988). The theory focuses on the interrelationship among product-meaning at three levels of abstraction: attributes, consequences, and values (Goldenberg et al., 2000). Attributes, 
which refer to the characteristics or features of the product, object or activity in question, are viewed as being relatively concrete. Examples of key "product" attributes for an outdoor adventure experience would include the length of the course, location of the course, activities done while on course, the instructor(s), and the number and nature of individuals in the group. Consequences, which refer to outcomes associated with particular attributes, are viewed as being more abstract. Consequences can refer to desired outcomes, more commonly called benefits, and also to undesirable outcomes, such as costs and perceived risks. Some examples of positive consequences/benefits for participants completing an outdoor adventure experience may include learning to work together with others in a group, acquiring skills needed to function in outdoor settings, or learning one's limitations and strengths as an individual or group member. Values summarize desired end-states of being and are viewed as being highly abstract (Goldenberg et al., 2000). Examples of values for participating in an outdoor adventure experience include transference, self-esteem, warm relationships with others, and a sense of accomplishment.

Instead of treating the three elements (attributes, consequences, and values) independent of each other, means-end theory views them as fundamentally interrelated. According to the theory, product/service attributes represent the "means" by which consumers obtain desired consequences/benefits (as well as avoid undesired consequences/costs) and achieve important personal values or "ends" (Gutman, 1982). This sequence of relationships linking attributes with consequences, and consequences with personal values, is summarized in the form of a set of associated meanings called a "means-end chain." As an example, a means-end chain in an outdoor adventure experience might link the attribute or course component "whitewater canoeing" (canoeing), to the consequence/outcome "learn important communication skills" (communication), and this consequence to the value, "now that I learned how to communicate better, I can get my point across" (self-awareness).

\section{Methodology}

\section{Measuring and Collecting Means-End Data}

This study uses means-end analysis to examine the attributes, consequences, and values associated with participating in an Outward Bound course. Means-end data is usually collected using a qualitative research technique known as "laddering" (Reynolds \& Gutman, 1988). Laddering involves asking a series of open-ended questions that first ask the respondent to identify the attributes of a product, or as in the present case, the outcomes that were important to them that they feel they received from 
participating in a given activity. The respondent is then asked why a particular outcome was important. The response given, which will typically refer to another, more abstract consequence will then be the focus of the next, "Why is that important?" question. This process of asking, "Why is that important?" continues for each response given until the respondent can no longer provide a meaningful answer (e.g., the response is "I don't know," or "It just is..."). The procedure is called laddering because it forces the respondent up the "ladder of abstraction," bridging relatively concrete concepts at the outcome or benefit level to more abstract concepts at the value level (Klenosky et al., 1993).

While the use of interviews, either conducted in person (Hofstede, Audenaert, Steenkamp, \& Wedel, 1998; Klenosky, 2002; Klenosky, Templin, \& Troutman 2001; Reynolds \& Rochon, 1991; Roth, 1994) or via phone (Bagozzi \& Dobholkar, 1994), has remained the preferred and most popular approach to collecting means-end data, a number of other studies have demonstrated that means-end data can also be collected using selfadministered questionnaires (Frauman \& Cunningham, 2001; Goldenberg et al., 2000; Pieters, Bottschen, \& Thelen, 1998; Walker \& Olson, 1991). The use of questionnaires is particularly helpful when working with large sample sizes and has proven to be a useful, cost-effective approach for collecting laddering data.

Regardless of whether data are collected using interviews or questionnaires, the analysis of laddering data involves several basic steps (further details about the steps and considerations involved in analyzing laddering data can be found in Klenosky et al., 1993, and Reynolds and Gutman, 1988). In the first step, the data are reviewed by the researcher(s), and content codes are developed based on participants' responses to the laddering process. The coded ladder elements are aggregated and used to develop an implication matrix-i.e., an asymmetric matrix that summarizes the number of times each concept was associated with each of the other concepts in respondents' ladders (Klenosky et al., 1998). Based on the relationships identified in the implication matrix, a hierarchical value map (HVM) is created. The HVM provides a graphical summary of the linkages that emerged across participants' ladders. Depending on the study's objectives, the results of a means-end investigation may be summarized in a single HVM for the entire sample of respondents, or in a series of HVMs focusing on specific study concepts. The present study shows the utility of this latter approach by describing the means-end relations associated with selected Outward Bound course components through a series of HVMs.

\section{Study Setting}

Participants for this research study attended an Outward Bound program conducted at the North Carolina Outward Bound School (NCOBS) 
during the summer of 2001. The NCOBS courses were based at three different base camps. The courses offered during the time period of the present study included rock skills courses, a rafting course, an educator course, a Girl Scout course, and public courses. Of the 30 courses offered during the study period, most (27) were public courses, while the remaining three were contract courses (courses designed for a specific group). Each contract course was customized to emphasize certain skills. For example, the rock skills courses focused on rock climbing, whereas the rafting courses specifically worked on the skills needed to raft on whitewater rivers.

Each study participant completed specific course components, such as backpacking, canoeing, rock climbing, solo, service project, and a personal challenge event. Most NCOBS courses included backpacking as one course component. Backpacking included basic campcraft skills (such as tarp set-up, cooking, and leave-no-trace techniques) and navigation skills (using a map and compass). Canoeing was conducted on fast-flowing, Class I-III, white-water rivers and was taught in a three-day progression to participants on courses lasting at least 21 days. Rock climbing was a oneto eight-day course component. Participants learned a range of rock climbing skills that included tying knots, belaying (supporting the climber with a safety rope), movement on rock, rappelling, and anchor placement. Solo was a part of most courses and was anywhere from a few hours to three days. It was designed to give participants a time to reflect, spend time alone, and relax during the course. Service was incorporated into all courses, but a formal service project was not necessarily included. Some formal service projects included working with a trail group to help maintain a trail, or building a bridge over a small river. A personal challenge event (PCE) was the event, usually at the end of a course, where individuals had the opportunity to challenge themselves physically and mentally. PCEs included a run, a high-impact rappel, or a navigationally challenging obstacle course.

\section{Data Collection Procedures}

The self-administered questionnaire adopted from Goldenberg et al. (2000), Walker and Olson (1991), Botschen and Hemetsberger (1998), and Pieters et al. (1998) was used to collect data from the study participants in the summer of 2001. This method was used to obtain a larger sample size than could have been achieved from interviews, and there is indication in the literature that the self-administered approach can be used effectively. The instrument consisted of two sections. The first section gathered data on participant demographics and program experiences, and the second section operationalized the laddering procedure. In the second section, participants were asked to list the key outcomes they obtained from the 
Outward Bound course they had just completed. Specifically, they were asked to "think about the things you learned and the outcomes you received from participating in this course," and to list these outcomes in the space provided. They were then instructed to select their most important outcome and explain why that outcome was important to them. They wrote their response in a box to the right of that outcome. They were then asked to explain why that response was important ("and this is important to you because...") and instructed to enter their response in the next box. This process was continued one more time. As a final step, participants were asked to indicate which part(s) of the course led them to learn this specific outcome. The series of responses linking a particular course component (attribute) to one or more outcomes (consequences), and these outcomes to one or more personal values represented a means-end chain, or ladder, of associated meanings.

Questionnaires were distributed at the conclusion of each NCOBS course by the study's lead researcher. Participants completed the questionnaires individually in a group setting. No incentives for respondents were used. A total of 294 questionnaires were distributed, and of these, 207 were returned, representing a response rate of $70.4 \%$. To explore the potential impact of non-response bias, phone interviews were conducted with nine non-respondents. No significant differences were found between respondents and non-respondents regarding demographic characteristics, course satisfaction ratings, and the number and types of outcomes obtained. The data from these nine respondents were combined with the respondent data yielding a final sample of 216 study participants.

\section{Analysis and Results}

\section{Participant Demographics}

Study participants ranged in age from 14-66 years old, with the majority $(90.3 \%)$ between 14 and 17 years old. Participants completed courses ranging in length from 4 to 21 days, with half (54.6\%) lasting 21 days. The majority were male $(57.4 \%)$, white $(84.3 \%)$, and high school students $(90.3 \%)$. One-fourth (25\%) received some sort of scholarship to attend NCOBS.

\section{Outcome Analysis}

Study participants were asked to list the outcomes they felt they received from their Outward Bound experience. A total of 799 outcomes were listed by the 216 participants, with a mean of 3.7 outcomes per respondent. Of these outcomes, those listed most frequently included physical fitness (listed by $34.7 \%$ of the study participants), followed by relationships with others $(20.8 \%)$, self-confidence $(19.9 \%)$, self-reliance 
(16.7\%), appreciation (16.7\%), teamwork/cooperation (15.7\%), personal growth/challenges (15.7\%), and knowledge/awareness (15.3\%).

\section{Analysis of Ladders Obtained}

The 216 study participants completed a total of 711 ladders, representing a mean of 3.3 ladders each. These ladders consisted of a total of 2,645 concepts or links, with a mean of 3.7 concepts. The concepts making up the respondents' ladders were coded by the researcher and a research assistant, and entered into LadderMap (Gengler \& Reynolds, 1995) computer program to facilitate data coding and analysis. As the concepts were entered into the program, "content codes" were developed based on phrases and key words that emerged from the data. This approach is similar to the "cut-up-and-put-in-folders" approach (Bogdan \& Bilken, 1982) which has been used successfully in prior recreation (Hultsman, 1996), and means-end research (Goldenberg et al., 2000). The content codes were developed first by two researchers working together, then by an independent coder who agreed on approximately $70 \%$ of the original coding assignments. This level of intercoder agreement is similar to that obtained in prior means-end research (Goldenberg et al., 2000; Klenosky et al., 1993). Coding disagreements were resolved based on discussions with two other researchers.

Table 1 summarizes the 36 content codes that were generated using this process. These codes consisted of 14 attributes, 14 consequences, and 8 personal values. The attributes that were mentioned most often across respondents' ladders included course overall (mentioned by $44.9 \%$ of the study participants and accounting for $5.9 \%$ of the concepts mentioned in participants' ladders), as well as more specific course components including: interactions (mentioned by $22.2 \%$ ), rock climbing $(20.8 \%)$, expeditioning $(19.4 \%)$, campcraft $(13.4 \%)$, and the solo experience $(13.0 \%)$. Interactions included any time a participant mentioned some type of interaction with another individual. These interactions included crew conflicts, crew interactions, meals, crew tasks, free time, etc. Expeditioning included navigational skills, hiking, and backpacking. Expeditioning occurred any time a group moved from one area to another, and almost always involved backpacking.

The consequences/outcomes mentioned most frequently in participants' ladders included: relationships with others/teamwork (mentioned by $51.9 \%$ ), knowledge/awareness (63.0\%), personal growth/challenges (48.6\%), and determination/perseverance (26.9\%). Relationships with others/teamwork was a very large category and included components such as building relationships, working as a team, communicating with others, compassion, cooperation, encouragement, being positive, friendships, respect, teaching, and trust. Knowledge/awareness included gaining 
knowledge in general, learning about outdoor and backcountry survival skills, and learning about oneself. Personal growth/challenges included developing abilities, new opportunities, personal challenges, personal growth, and problem-solving. Determination/perseverance included overcoming fears, getting motivated, and developing endurance.

Finally, of the eight values identified, those mentioned most frequently included transference (mentioned by $58.3 \%$ ), self-awareness/ improvement/fulfillment (49.5\%), achievement of a personal goal/value $(39.8 \%)$, and self-confidence/esteem $(34.3 \%)$. Transference referred to transferring the skills and knowledge obtained through their experience to work, school, other activities, and to life in general. Any time an individual referred to being able to apply a skill to one or more areas outside of their Outward Bound experience, it was coded as a form of transference. The other values mentioned were fairly self-explanatory.

\section{Means-End Relations}

In order to summarize the means-end relations among the attributes, consequences, and values identified, a set of implication matrices and hierarchical value maps (HVMs) were developed. The HVMs were created based on the approach recommended by Gengler, Klenosky, and Mulvey (1995). Using this approach, the concepts in the HVM are represented as circles. The size of the circle is set proportionally to the number of times the concept was mentioned by study participants in the implications matrix, and the thickness of the lines connecting circles proportional to the number of times concepts were linked together. Value-level concepts are represented using black circles located near the top of the HVM and labeled using all upper-case letters. As noted by Klenosky et al. (1998), this approach reflects the highly abstract role that values play in defining the meaning of the other, more concrete consequences/outcomes and attribute concepts. Consequences are represented as grey circles positioned in the middle of the map and labeled using initial capitals only. Attributes/course components are represented as white circles positioned at the bottom of the map and labeled in all lower-case letters.

Figure 1 summarizes the concepts and associations generated from all the respondents who participated in this study $(n=216)$. To simplify interpretation, only those associations mentioned by at least nine respondents are represented in this summary HVM. The predominant attributes/course components illustrated on this map included the course overall, rock climbing, expeditioning, and interactions. Other represented course components included campcraft, solo, PCE, leadership opportunities, and instruction. The consequences that were mentioned most frequently included knowledge/awareness, personal growth/challenges, and relationships with others/teamwork. Other notable outcomes included 
Table 1.

Number of Times Concepts Mentioned in Respondents' Ladders

\begin{tabular}{|c|c|c|}
\hline ATTRIBUTES MENTIONED & $\begin{array}{l}\text { of Respondents } \\
\text { oning Concept } \\
\text { Least Once }\end{array}$ & $\begin{array}{c}\text { Percent of Respondents } \\
\text { Mentioning Concept } \\
\text { at Least Once }\end{array}$ \\
\hline Course Overall & 97 & 44.9 \\
\hline Interactions & 48 & 22.2 \\
\hline Rock Climbing & 45 & 20.8 \\
\hline Expeditioning & 42 & 19.4 \\
\hline Campcraft & 29 & 13.4 \\
\hline Solo & 28 & 13.0 \\
\hline Course Challenges & 17 & 7.9 \\
\hline Instruction & 15 & 6.9 \\
\hline New Experiences & 14 & 6.5 \\
\hline PCE & 13 & 6.0 \\
\hline Leadership Opportunities & 11 & 5.1 \\
\hline Canoeing & 10 & 4.6 \\
\hline Course Beginning/Completion & 8 & 3.7 \\
\hline Environment & 8 & 3.7 \\
\hline \multicolumn{3}{|l|}{ CONSEQUENCES MENTIONED } \\
\hline Knowledge/Awareness & 136 & 63.0 \\
\hline Relationships with Others/Teamwork & 112 & 51.9 \\
\hline Personal Growth/Challenges & 105 & 48.6 \\
\hline Determination/Perseverance & 58 & 26.9 \\
\hline Physical Fitness & 52 & 24.1 \\
\hline Appreciation & 38 & 17.6 \\
\hline Independence & 36 & 16.7 \\
\hline Nature Appreciation & 28 & 13.0 \\
\hline Leadership & 26 & 12.0 \\
\hline Efficient & 17 & 7.9 \\
\hline Achievement & 16 & 7.4 \\
\hline Reflection & 16 & 7.4 \\
\hline Survival & 15 & 6.9 \\
\hline Patience & 12 & 5.6 \\
\hline \multicolumn{3}{|l|}{ VALUES MENTIONED } \\
\hline Transference & 126 & 58.3 \\
\hline Self-Awareness/Improvement/Fulfillment & 107 & 49.5 \\
\hline Achievement of a Personal Goal & 86 & 39.8 \\
\hline Self-Confidence/Esteem & 74 & 34.3 \\
\hline Fun and Enjoyment of Life & 64 & 29.6 \\
\hline A Sense of Accomplishment & 57 & 26.4 \\
\hline Self-Reliance & 40 & 18.5 \\
\hline Warm Relationships with Others & 30 & 13.9 \\
\hline
\end{tabular}

Note. $n=216$. 
determination/perseverance and physical fitness. The value mentioned most frequently was transference. Additional values included self-awareness/improvement/fulfillment, achievement of a personal goal/value, selfconfidence/esteem, and sense of accomplishment. It is notable that several participants linked the overall course with physical fitness, relationships with others/teamwork, and nature appreciation.

Several concepts were associated with, or linked to, the consequence of relationships with others/teamwork. The attributes involved in these linkages were the overall course experience, expeditioning, rock climbing, and interactions. Rock climbing was linked to relationships with others/teamwork and also to determination/perseverance. Relationships with others/teamwork linked to the outcome increased knowledge/awareness and to the value warm relationships with others. This suggests that working with others throughout the course, expeditioning, rock climbing, and interactions, help participants learn to work as a team. This helped them get along and develop "warm" relationships with others. Another strong link observed in the HVM involved the links between personal growth/challenge and self-confidence/esteem, and between self-confidence/esteem and a sense of accomplishment. This set of relations suggested that as individuals challenged themselves and grew, they felt better about themselves, which was associated with the feeling of accomplishment in life. Participants also appeared to appreciate the leadership opportunities they experienced on the course, that they apparently viewed as a skill that could potentially be transferred to other aspects of their lives. Finally, the links involving the solo experience (i.e., being alone outdoors for a given length of time) led the participants to feel more independent and self-reliant, which was associated with gaining knowledge and enhancing personal awareness.

In addition to the summary HVM shown in Figure 1, separate HVMs were developed to provide a more refined view of the outcomes associated with five key Outward Bound course components: rock climbing, interactions, expeditioning, campcraft, and the solo experience. These HVMs can be found in Figures 2, 3, 4, 5, and 6 respectively. To simplify interpretation, only those associations mentioned by at least two respondents are represented in these HVMs.

The HVM for rock climbing, shown in Figure 2, had several associations that stood out. Determination/perseverance and relationships with others/teamwork were the strongest associations directly associated with rock climbing. This makes sense, as rock climbing leads to individuals working together, as well as individuals pushing themselves and showing both determination and perseverance while climbing. Other consequences linked either directly or indirectly to rock climbing included knowledge/awareness, personal growth/challenge, physical fitness, independ- 


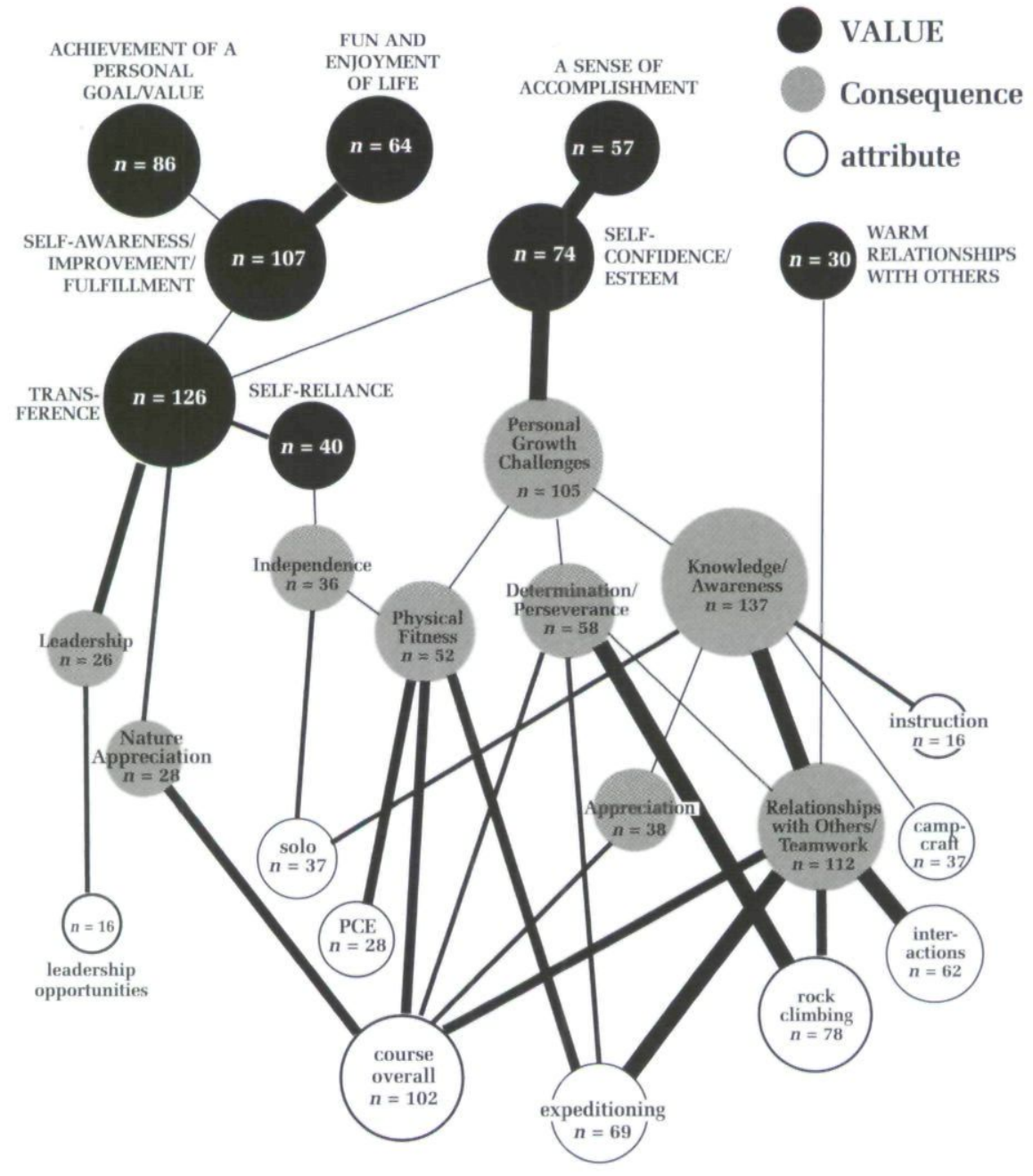

Figure 1. Hierarchical value map for Outward Bound course participants: All respondents $(n=216)$.

ence, appreciation, and achievement. The values that linked with these outcomes, most frequently included self-awareness/improvement/fulfillment, self-confidence/esteem, and transference. Taken together, the outcomes and values associated with rock climbing are consistent with the view of rock climbing as being primarily an individual or personal growth-oriented form of experiential education.

As would be expected, in the HVM for interactions shown in Figure 3 , the most frequently mentioned concept was the consequence relationships with others/teamwork. Other consequences linked with interactions 
included knowledge/awareness, personal growth/challenges, reflection, patience, appreciation, and leadership. Notable values that linked with these outcomes included self-awareness/improvement/fulfillment, transference, fun and enjoyment in life, and warm relationships with others. The interrelationships involving these concepts suggest that the interactions experienced while on an Outward Bound course help participants learn to work with others to get tasks accomplished, as well as appreciate and develop relationships with others that will extend beyond the course itself.

The HVM for expeditioning, shown in Figure 4, showed that enhanced physical fitness and leadership skills had the strongest direct links for this course component. Other notable outcomes for expeditioning included appreciation, survival, independence, and patience. Transference was the most frequently mentioned value in this HVM. The outcomes and values depicted in this HVM differ considerably from those shown in the rock climbing HVM, suggesting that expeditioning and rock climbing provide different types of experiences for Outward Bound course participants.

In the HVM for campcraft, shown in Figure 5, the most prominent consequence was knowledge/awareness. This consequence was linked to campcraft through the outcomes efficient and nature appreciation. The most frequently mentioned value in this HVM was transference. The pattern of interrelationships depicted indicates that learning how to camp and survive in the outdoors was useful information that participants appreciated, and wanted to use and share with others after the course was over.

Finally, in the HVM for the solo experience, shown in Figure 6, the strongest association was between solo and independence. This link makes sense, because when participants were on solo, they were on their own and needed to take care of their basic needs independently. Other consequences directly associated with solo included survival, nature appreciation, reflection, determination/perseverance, relationships with others/teamwork, and physical fitness. The consequence-relationships with others/teamwork, and the value-warm relationships with others, seemed unlikely to be associated with the solo, but they did appear on this HVM. This suggests that the opportunity to be alone and on one's own in nature leads one to appreciate working with, and being with other people. Other values mentioned most frequently in this HVM depicted transference, self-reliance, and self-awareness. This set of outcomes and related meanings appears to reflect the intended role of the solo experience in the Outward Bound program.

\section{Discussion}

The overall goal of this research was to develop a better understanding of the outcomes associated with completing a multi-day Outward 


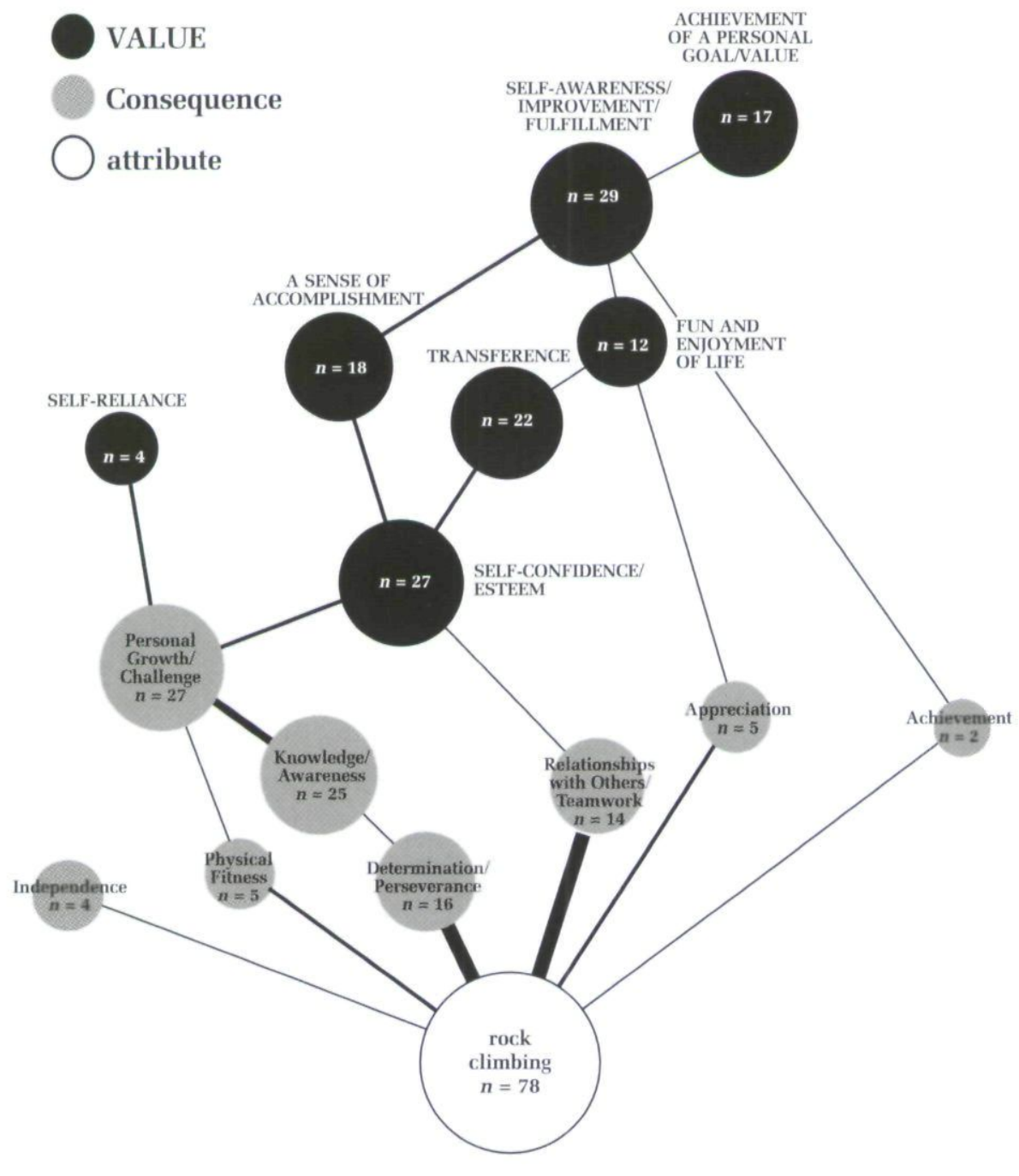

Figure 2. Hierarchical value map for Outward Bound course component: Rock climbing $(n=78)$.

Bound course. Using means-end theory and a self-administered laddering approach, data collected from a sample of Outward Bound course participants provided useful insight into the outcomes associated with this form of experiential education programming; and the means-end linkages that helped explain how and why these outcomes obtain their meaning in an Outward Bound course.

An analysis of the data across all respondents revealed a number of key outcomes and personal values that appear to be consistent with those 
reported in prior investigations in the outdoor adventure and experiential education literature. For instance, Hattie et al. (1997) reported that outdoor adventure programs have an impact on participants' awareness of themselves and others. Self-awareness/improvement/fulfillment was the second most frequently mentioned value in the present study. Hattie et al. also stated that participants' awareness of others increased while they were involved with an outdoor adventure activity. Other researchers (Ewert \& Heywood, 1991; Fielding \& Hogg, 1997) have found that outdoor adventure programs have positive impacts on group dynamics and development. These findings were supported in this study as well, in that, developing relationships with others and working as a team emerged as one of the most commonly mentioned consequences; and appeared to play a key role when participants interacted and worked together to rock climb, canoe, or expedition during the course. Prior research by Paxton and McAvoy (2000) examined how self-efficacy from participating in an outdoor adventure activity is transferred to participants' daily lives. In the current study, transference (i.e., the transference of skills and knowledge to work, school, and life) was the most frequently mentioned value, and was frequently linked to other values related to feelings of self-confidence, accomplishment, and self-fulfillment.

The results of this research complement the findings reported by Estes (1994), who examined whether the core values or principles espoused by Outward Bound were conveyed in general, as well as through specific course components. Although the course components examined differed between the two studies, the findings of both studies had some interesting similarities. For instance, consistent with the Estes findings, the HVMs for general or frequently occurring course elements, such as the course overall, interactions, and expeditioning, tended to involve a larger number of concepts and links compared to the HVMs for more specific course components, such as rock climbing and campcraft. In addition, the items rated as among the most important by course participants in Estes' study involved the principles cooperation, compassion, and self-discovery. Similar concepts that emerged as central in the present study included outcomes and values, specifically the consequence relationships with others/teamwork, and the values warm relationships and self-awareness/improvement, that reflect similar underlying principles.

In sum, Ewert and McAvoy (2000) encouraged researchers to look at the "how and why" of programming, versus only looking at the "what and when" of the program. The present study provided some of the answers that address how and why specific outcomes occur for individuals from completing an outdoor adventure experience. It also provided insight into how outdoor professionals can facilitate these outcomes by incorporating specific course elements or experiences into the programs they design. 

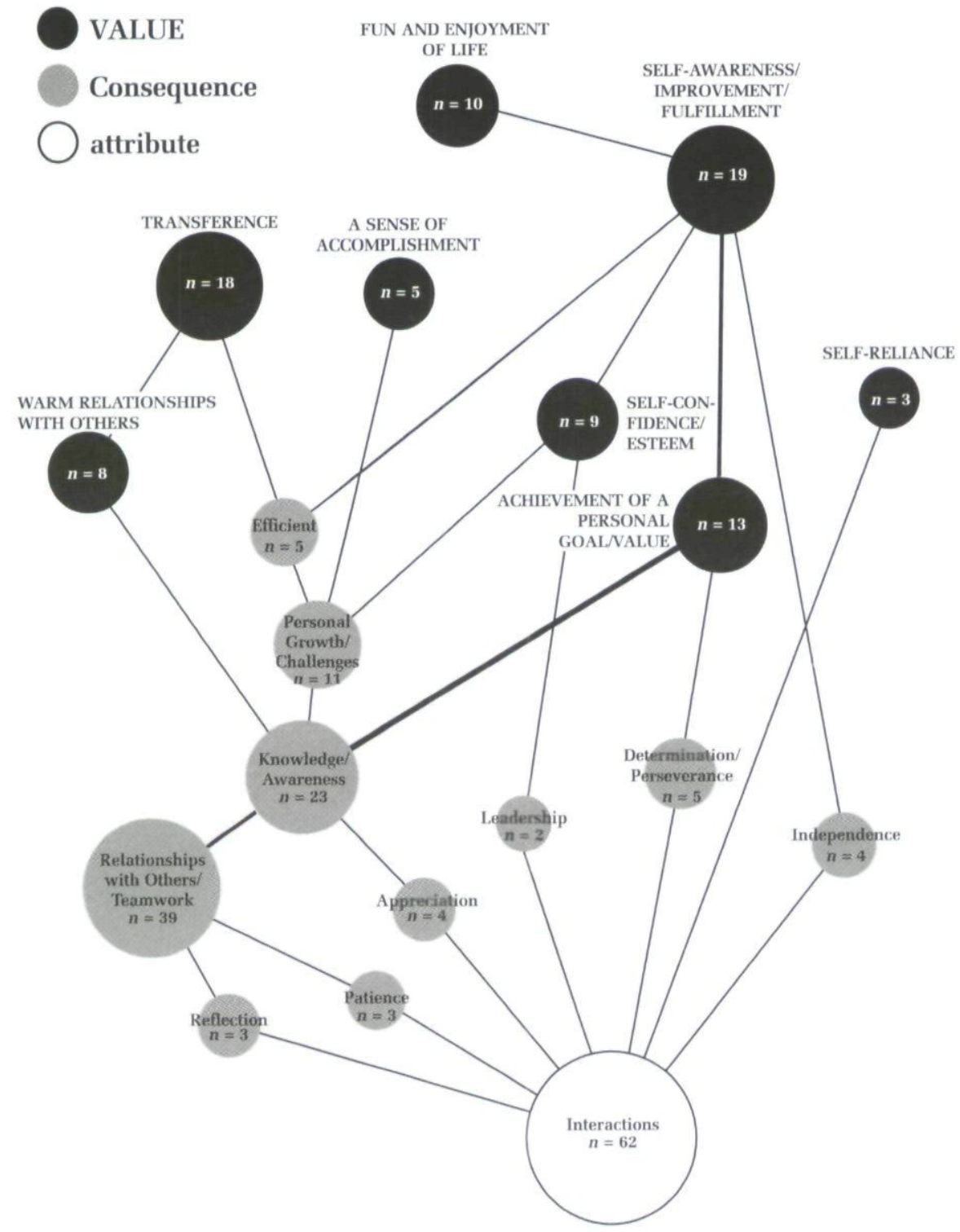

Figure 3. Hierarchical value map for Outward Bound course component: Interactions $(n=73)$. 


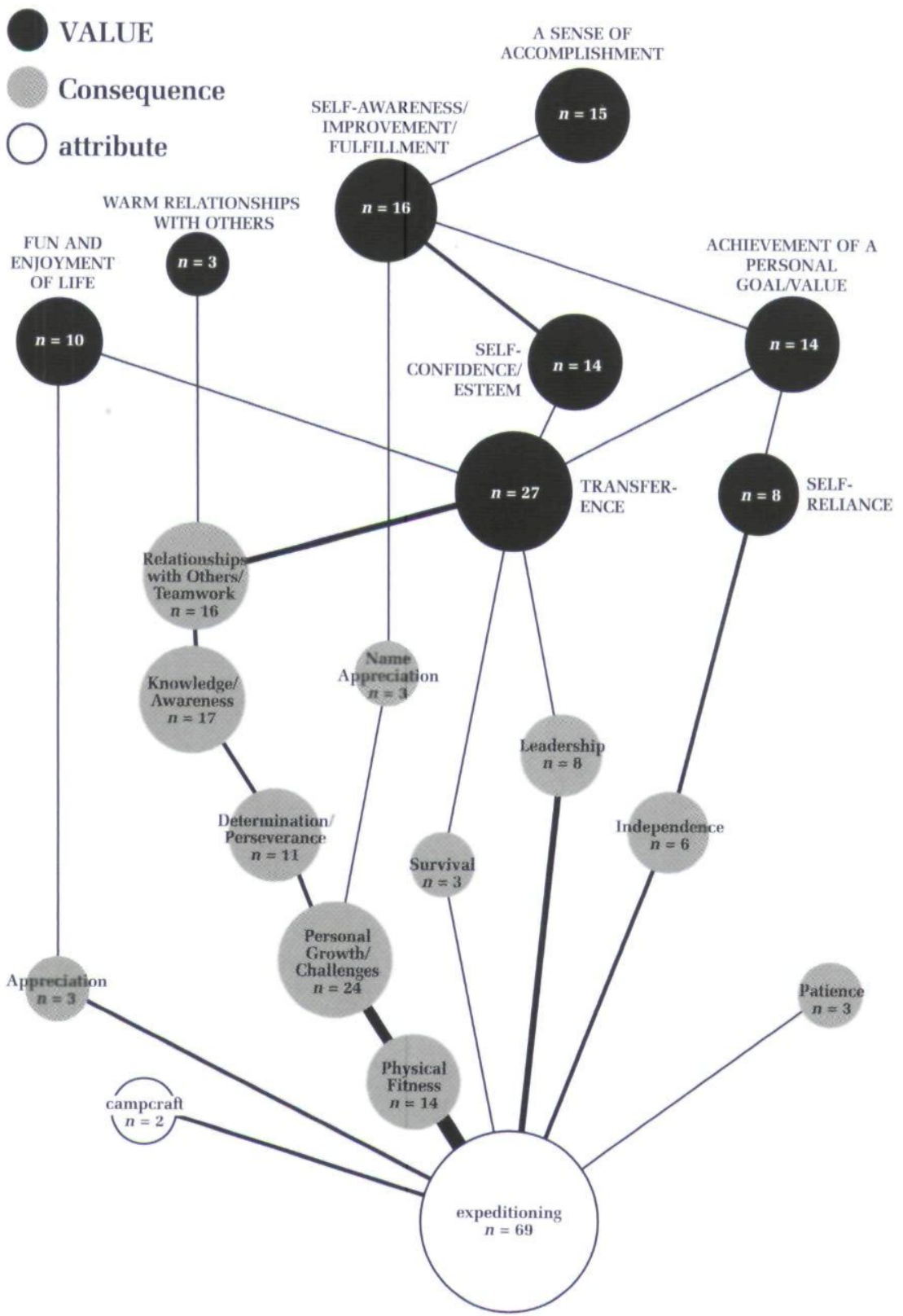

Figure 4. Hierarchical value map for Outward Bound course component: Expeditioning $(n=69)$. 


\section{VALUE}

\section{Consequence}

attribute

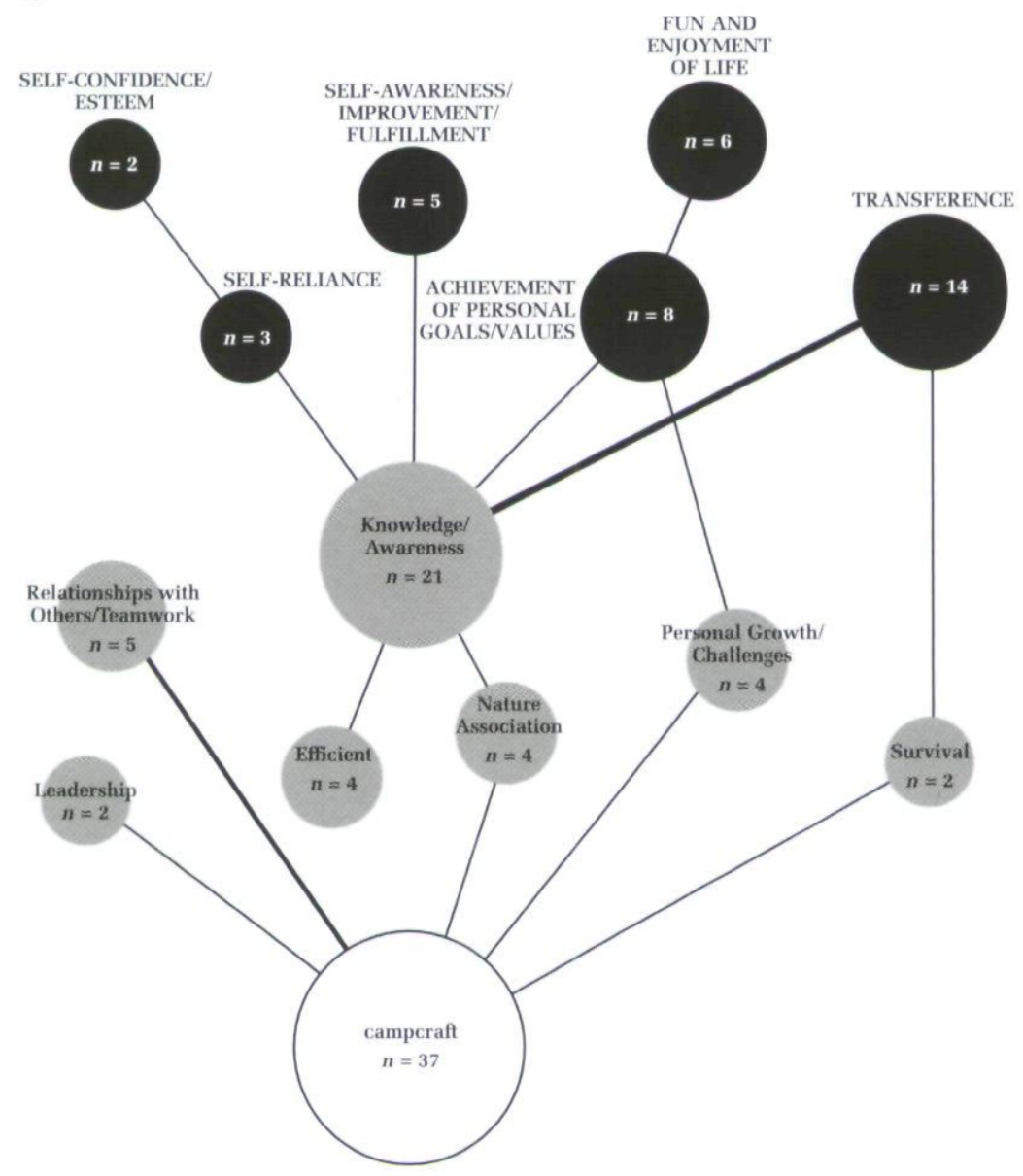

Figure 5. Hierarchical value map for Outward Bound course component: Campcraft $(n=44)$. 


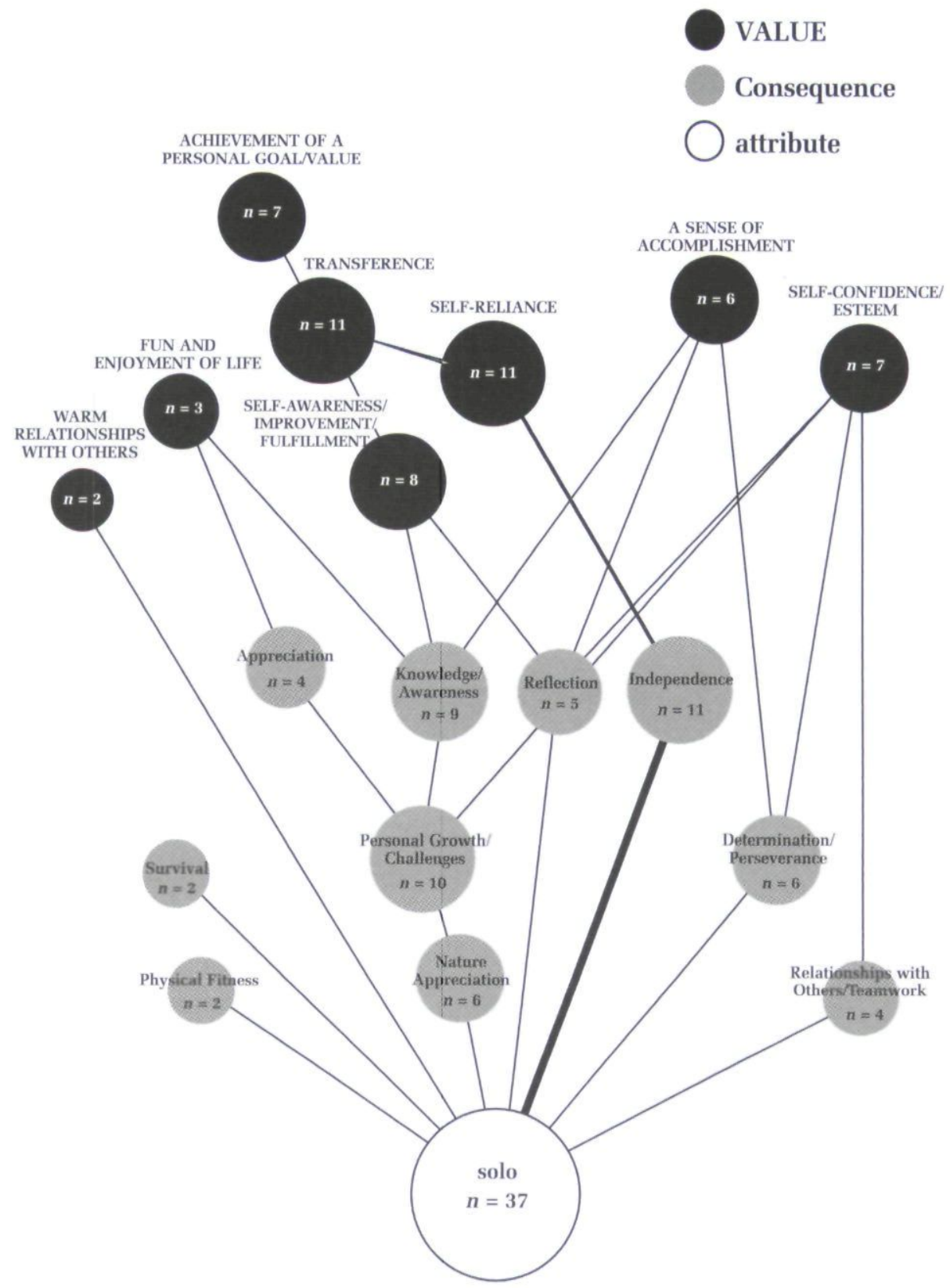

Figure 6. Hierarchical value map for Outward Bound course component: Solo $(n=37)$. 


\section{Implications}

The results of this study present several implications for practice in Outward Bound and similar outdoor adventure programs. Chief among these is using knowledge of the outcomes associated with specific course elements during program design. Course components that are likely to lead to specific outcomes and personal values can be targeted for a specific clientele.

Knowledge of potential course component outcomes can also be used to market or "sell" a certain type of program. The outcomes obtained from course participation can be printed on marketing material and shared with potential participants as they learn about an outdoor adventure experience they may pursue in the future. Moreover, managers of Outward Bound and similar types of adventure programs can also use the results from this study to better obtain grant funding and donations. Funding sources often seek research results to document or evaluate program outcomes and course effectiveness. The data generated from this study could be used to provide such evidence. Finally, the results from this study can also help with the training of staff who instruct outdoor adventure programs. Part of the training for instructors should include developing an awareness of the potential outcomes that participants may receive from being part of a program, or from particular program elements. This knowledge could be used by instructors to design and shape program elements to meet specific outcomes.

In addition to these practical implications, there are several interesting implications for future research in outdoor adventure programming. Some of these directly relate to the limitations of this research, while others expand the application of means-end analysis in the outdoor adventure field. One key concern relates to the sample used for this study. Most of the study participants were students between 14-18 years old who were primarily Caucasian. Future research could be conducted using different age groups, males compared to females, and different demographic populations. Specific subgroups to explore may include youth-at-risk, physical or mental health patients, corporate groups, and young professionals in the outdoor field. Outward Bound also runs courses for individuals that know each other, such as school groups, parent/child courses, or couple courses versus open-enrollment courses where individuals do not know each other. It would be interesting to see if results from these pre-formed groups would be similar to the results from the current study.

A follow-up study of multi-day experiences after a given length of time is recommended. This research was collected immediately following the participant's course and it would be interesting to compare these results with perceived outcomes within a five- to ten-year time period fol- 
lowing participation in an outdoor adventure program. For example, future research could be conducted to explore the issue of whether transference, one of the major values noted by participants in the present study, did in fact occur.

The outcomes of other outdoor adventure activities could also be examined using means-end analysis. Examples of these activities include canoeing, kayaking, rafting, mountain biking, winter camping, or downhill skiing. The outcomes from these various outdoor adventure activities may vary from this current study, and this would be a useful contribution to the outdoor adventure literature.

In conclusion, this research revealed that outdoor adventure education programs make an immediate impact in the lives of participants. Through this study, it was possible to better understand the outcomes provided by Outward Bound outdoor adventure experiences, and appreciate how these outcomes contribute to the development and reinforcement of important personal values. These values are believed to positively impact participants' lives long after the outdoor adventure experience is over. Additional studies are needed to take this research to the next level and examine the nature and significance of these longer term outcomes.

\section{References}

Bagozzi, R., \& Dobholkar, P. (1994). Consumer recycling goals and their effect on decision-making to recycle: A means-end chain analysis. Psychology $\&$ Marketing, 11(4), 313-340.

Bogdan, R., \& Bilken, S. (1982). Qualitative research for education: An introduction to theory and methods. Boston: Allyn \& Bacon.

Botschen, G., \& Hemetsberger, A. (1998). Diagnosing means-end structures to determine the degree of potential marketing program standardization. Journal of Business Research, 42, 151-159.

Caughron, D. (Ed.). (1998). North Carolina Outward Bound School Instructor Handbook. Ashville, NC: North Carolina Outward Bound School.

Bunting, C. (1990). Interdependency: A key in environmental and adventure education. In J. C. Miles \& S. Priest (Eds.), Adventure education (pp. 453-458). State College, PA: Venture.

Driver, B. L., Nash, R., \& Haas, G. (1987). Wilderness benefits: A state-of-knowledge review. In R. C. Lucas (Ed.), Proceedings of the National Wilderness Research Conference (General Technical Report No. INT-220, pp. 294-319). Ft. Collins, CO: USDA Forest Service.

Estes, C. A. (1994). Outward Bound: The congruence of principles and practice. In L. H. McAvoy, L. A. Stringer, \& A. Ewert (Eds.), Proceedings of the Coalition for Education in the Outdoors (pp. 22-32). Bradford Woods, IN. 
Ewert, A. (1987). Research in experiential education: An overview. Journal for Experiential Education, 10(2), 4-7.

Ewert, A. (1989). Outdoor adventure pursuits: Foundations, models, and theories. Columbus, OH: Publishing Horizons.

Ewert, A., \& Heywood, J. (1991). Group development in the natural environment: Expectations, outcomes, and techniques. Environment and Behavior, 23, 592-615.

Ewert, A., \& McAvoy, L. (2000). The effects of wilderness settings on organized groups: A state-of-knowledge paper. In S. McCool, D. Cole, W. Borrie, \& J. O'Loughlin (Eds.), Proceedings of the Wilderness Science in a Time of Change Conference, Volume 3: Wilderness as a Place for Scientific Inquiry (pp. 13-26). Washington, DC: USDA Forest Service.

Fielding, K., \& Hogg, M. (1997). Social identity, self-categorization, and leadership: A field study of small interactive groups. Group-Dynamics, 1(1), 39-51.

Frauman, E., \& Cunningham, P. H. (2001). Using means-end approach to understand the factors that influence greenway use. Journal of Park and Recreation Administration, 19(3), 93-113.

Gengler, C. E., Klenosky, D. B., \& Mulvey, M. (1995). Improving the graphic representation of mean-end results. International Journal of Research in Marketing, 12(3), 245-256.

Gengler, C. E., \& Reynolds, T. J. (1995). LadderMap [Computer Software]. Camden, NJ: Means-End Software.

Goldenberg, M. A., Klenosky, D. B., O'Leary, J. T., \& Templin, T. J. (2000). A meansend investigation of ropes course experiences. Journal of Leisure Research, 32(2), 208-224.

Gutman, J. (1982). A means-end chain model based on consumer categorization processes. Journal of Marketing, 46, 60-72.

Hattie, J., Marsh, H., Neill, J., \& Richards, G. (1997). Adventure education and Outward Bound: Out-of-class experiences that make a lasting difference. Review of Educational Research, 67(1), 43-87.

Hirsch, J. (1999). Developmental adventure programs. In J. C. Miles \& S. Priest (Eds.), Adventure programming (pp. 13-27). State College, PA: Venture.

Hofstede, F., Audenaert, A., Steenkamp, J., \& Wedel, M. (1998). An investigation into the association pattern technique as a qualitative approach to measuring means-end chains. International Journal of Research in Marketing, 15, 37-50.

Hultsman, W. (1996). Benefits of and deterrents to recreation participation: Perspectives of early adolescents. Journal of Applied Recreation Research, 21(3), 213-241.

Klenosky, D. B. (2002). The "pull” of tourism destinations: A means-end investigation. Journal of Travel Research, 40, 385-395.

Klenosky, D. B., Frauman, E., Norman, W., \& Gengler, C. (1998). Nature-based tourists' use of interpretive services: A means-end investigation. Journal of Tourism Studies, 9 (2), 26-36.

Klenosky, D. B., Gengler, C., \& Mulvey, M. (1993). Understanding the factors influencing ski destination choice: A means-end analytic approach. Journal of Leisure Research, 25(4), 362-379.

Klenosky, D. B., Templin, T. J., \& Troutman, J. A. (2001). Athletic recruiting: A means-end investigation of student athletes' school choice decisions. Journal of Sport Management, 15(2), 95-106. 
Martin, A. J. (2001). Towards the next generation of experiential education programmes: A case study of Outward Bound. Unpublished doctoral dissertation, Massey University, Palmerston North, New Zealand.

Neill, J. T., \& Richard, G. E. (1998). Does outdoor education really work? A summary of recent meta-analyses. Australian Journal of Outdoor Education, 3(1) $2-9$.

Paxton, T., \& McAvoy, L. (2000). Social-psychological benefits of a wilderness adventure program. In S. McCool, D. Cole, W. Borrie, \& J. O'Loughlin (Eds.), Proceedings of the Wilderness Science in a Time of Change Conference, Volume 3: Wilderness as a Place for Scientific Inquiry (pp. 202-205). Washington, DC: USDA Forest Service.

Pieters, R., Botschen, G., \& Thelen, E. (1998). Customer desire expectations about service employees: An analysis of hierarchical relations. Psychology $\&$ Marketing, 15(8), 755-773.

Priest, S. (1990). Semantics of adventure education. In J. C. Miles \& S. Priest (Eds.), Adventure education (pp. 113-117). State College, PA: Venture.

Raiola, E., \& O'Keefe, M. (1999). Philosophy in practice: A history of adventure programming. In J. C. Miles \& S. Priest (Eds.), Adventure programming (pp. 45-54). State College, PA: Venture.

Reynolds, T. J., \& Gutman, J. (1988). Laddering theory, method, analysis, and interpretation. Journal of Advertising Research, 28(1), 11-31.

Reynolds, T. J., \& Rochon, J. P. (1991). Means-end based advertising research: Copy testing is not strategy assessment. Journal of Business Research, 22, 131-142.

Roggenbuck, J. W., \& Driver, B. L. (2000). Benefits of nonfacilitated uses of wilderness. In S. McCool, D. Cole, W. Borrie, \& J. O'Loughlin (Eds.), Proceedings of the Wilderness Science in a Time of Change Conference, Volume 3: Wilderness as a Place for Scientific Inquiry (pp. 33-49). Washington, DC: USDA Forest Service.

Roth, M. S. (1994). Enhancing consumer involvement in health care: The dynamics of control, empowerment, and trust. Journal of Public Policy \& Marketing, 13(1), 115-132.

Todd, S. J., Anderson, L., Young, A. B., \& Anderson, D. (2002, April). Differences in motivations over time by level of development: An examination of pre/post adventure recreation experiences. Paper presented at the meeting of the Northeastern Recreation Research Symposium, Bolton Landing, NY.

Sibthorp, J. (2003). Learning transferable skills through adventure education: The role of an authentic process. Journal of Adventure Education and Outdoor Learning, 3(2), 145-157.

Walker, B. A., \& Olson, J. C. (1991). Means-end chains: Connecting products with self. Journal of Business Research, 22, 111-118. 
Copyright of Journal of Experiential Education is the property of Association for Experiential Education and its content may not be copied or emailed to multiple sites or posted to a listserv without the copyright holder's express written permission. However, users may print, download, or email articles for individual use. 